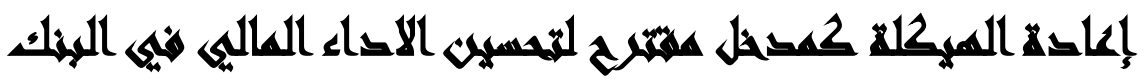

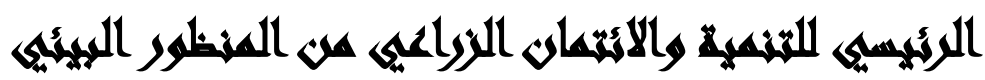

\section{[11]}

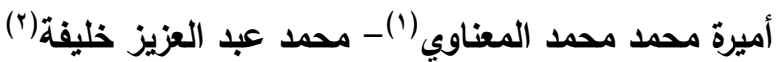

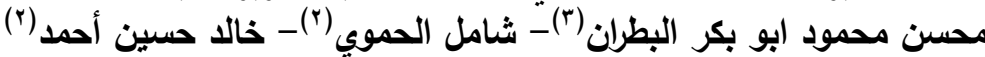

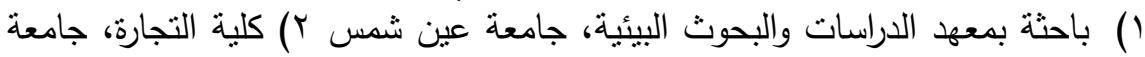
عين شمس ب) كلية الزراعة، جامعة القاهرة

\section{المستخليك}

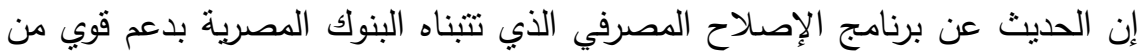

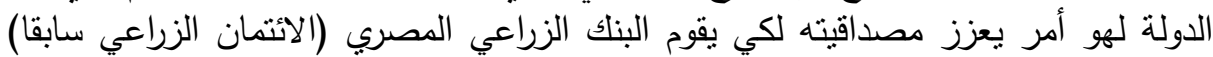

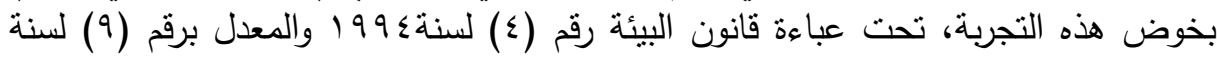

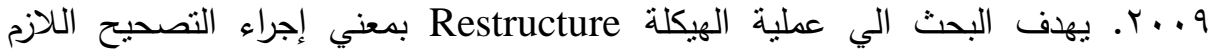

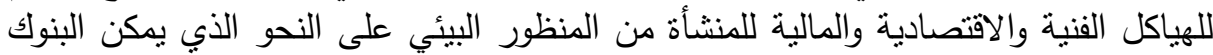

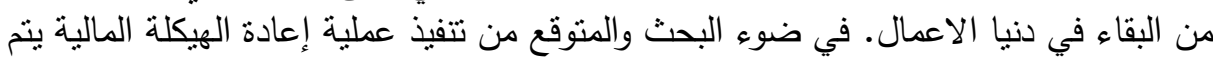

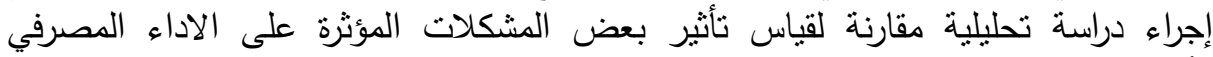

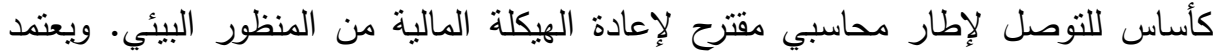

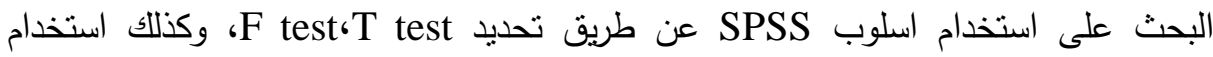

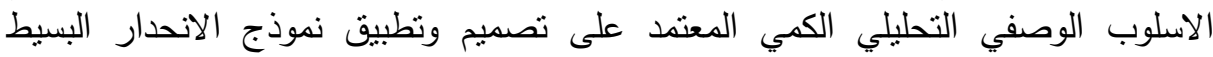

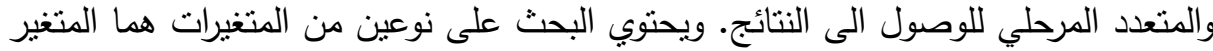

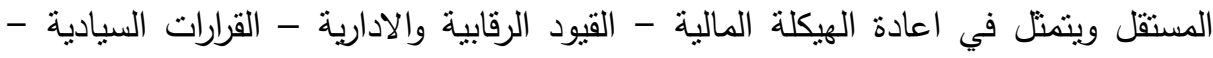

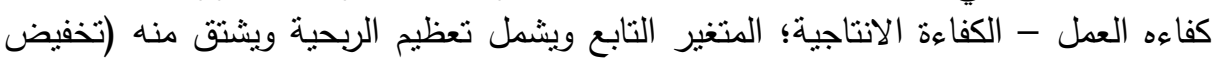

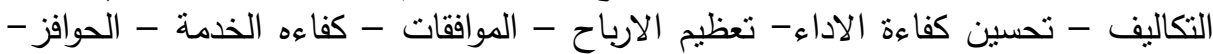
منظومة الائتمان والتسويق). ومما سبق تبين تعظيم الربحية بالبنك الزراعي المصري، وأن إعادئ إعادة الهيكلة المالية تؤثر

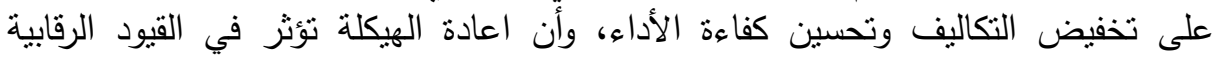

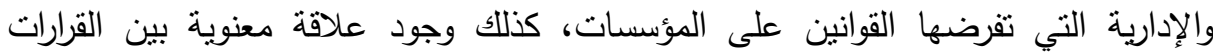
السياسية بالدولة ومدى كفاءة العمل في المؤسسات المالية ومنظومة الائتمان والتسويق.

$$
\text { المجلد السادس والأربعون، الجزء الأول، يونيه } 19 \text { ـ. }
$$


وقد أوصي البحث بأن البنوك بصفة عامة والبنك الزراعي المصري بصفة خاصة بالتركيز والاستغلال الامتل للموارد والفرص المتان الناحة والتزكيز على الميزة النسبية للبنك لتكون هذه الميزة هي نقطة الانطلاق للأمام باستخدام التكنولوجيا الحديثة.

\section{ranadl}

إن الحديث عن برنامج الاصلاح المصرفي الذي تتبناه البنوك المصرية بدعم قوي من

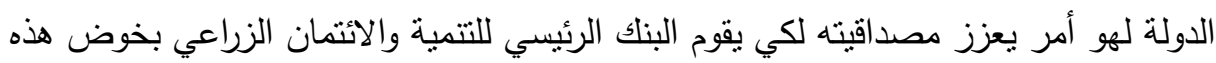

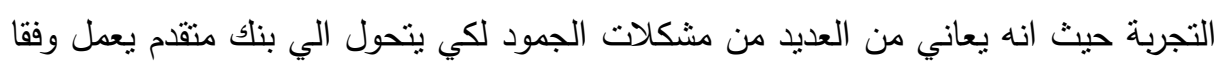

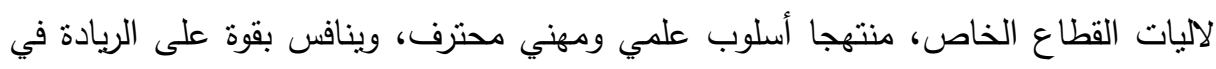

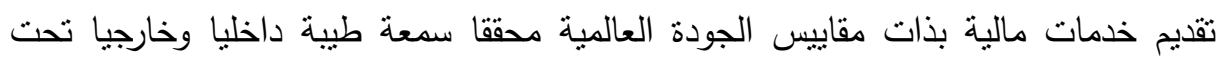

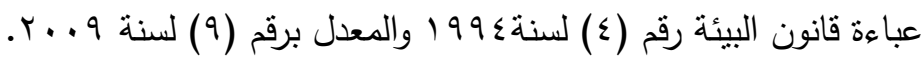
وتستهدف عمليات اعاده الهيكلة Restructure إجراء التصحيح اللازم للهياكل الفنية والاقتصادية والمالية للمنشأة من المنظور البيئي على النحو الذي يمكن البنوك من البقاء في

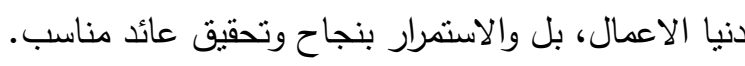
وهذا يتطلب إعادة التصميم الجذرى والسريع لعمليات المنظمة الإستراتيجية، وكذلك للنظم والسياسات والهياكل التتظيمية المدعمة لهذه العمليات لتعظيم تدفق العمل والإنتاجية.

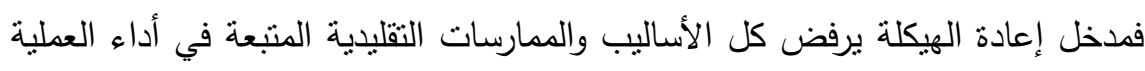

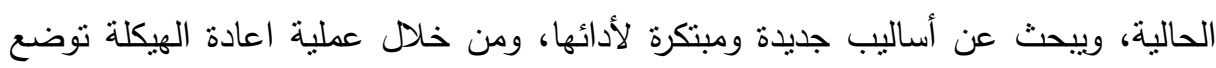
الأطر العامة والتفصيلية لجميع الاعمال والوظائف التى ستؤدى داخل المنظمة.

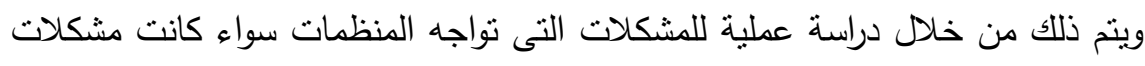
فنية وتكنولوجية أو مشكلات اقتصادية وتمويلية أو مشكلات تسويقية أو متعلقة باداء العمالة ومدى تقبل المجتمع والدولة للبنوك من اجل التصدى لاى مشكلات قانونية قد تتعرض لها.

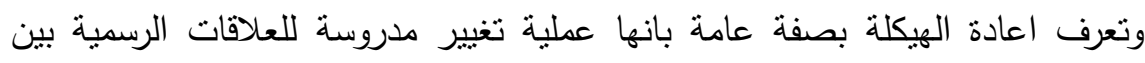

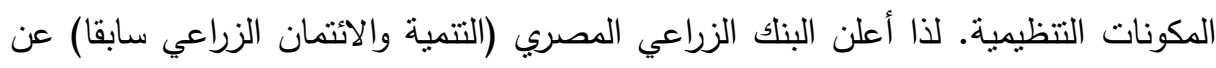

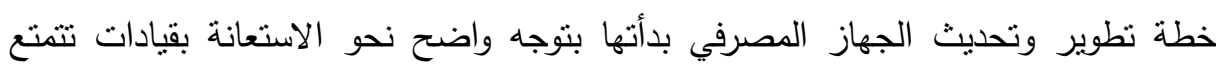
بخبرات متخصصة وتجمع بين الالمام بالواقع المصري والخبرة العالمية، فتم في هذا الاطار

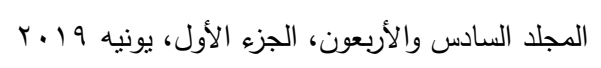


اسناد مسئولية الاصلاح الهيكلي لقيادات ذات خبرات دولية مشهود لها، اضطلعت بمهمة اعادة بناء البنك من الداخل وتطوير أدائه وفقا للآلّات السوق ومتطلباته من حيث طبيعته دئه الخاصة ومتمشيا مع المنظور البيئي الحديث.

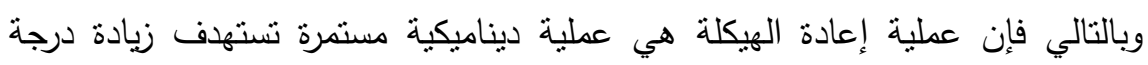
التنافسية لتحقيق أهداف البنوك، وزيادة الناتج القومي كهدف عام، لذلك فإن الامر يزداد سوءاء وتزداد المشكلة تعقيدا حينما يكون التدهور في البنوك يهدد قطاعا حيويا يمثل مصدرا أساسيا للاقتصاد القومي وخاصا القطاع الزراعي.

\section{Anand}

مما سبق يتضح أن المشكلة موضوع البحث تتركز في النقاط الأتية:

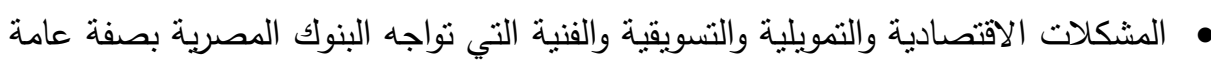
والبنك الزراعي المصري بصفة خاصة. • • زيادة حجم الديون المتأخرة للبنوك وغيرها من الدائنين. • انخفاض فائض العمليات الجارية وعدم مناسبة معدل العائد السنوي على راس المال

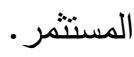
• أكل حقوق الملكية بسبب استمرار نزيف الخسائر.

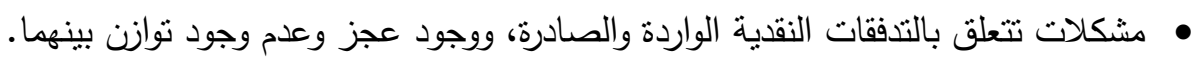
• • مشكلات متعلقة بكفاءة الادارة وحسن تصرفاتها أو أمانتها أو نزاهتها.

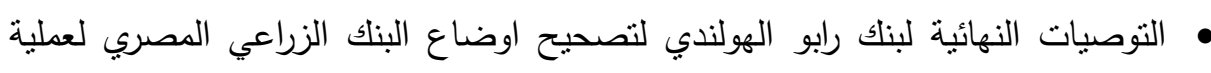

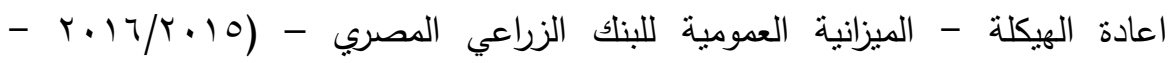

$$
\cdot(r \cdot 1 \mathrm{~V} / \mathrm{r} \cdot 17
$$

وتتمنل مشكلة البحث في سؤال جوهري هو : "ما إمكانية معرفة أثر نطبيق برنامج اعادة

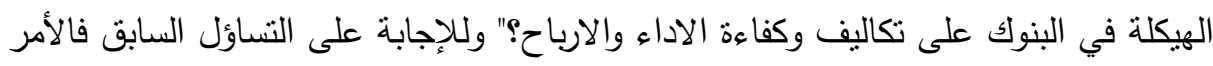
يتطلب الاجابة على التساؤلات الفرعية التالية:

$$
\text { المجلد السادس والأربعون، الجزء الأول، يونيه } 19 \text { ـ. }
$$




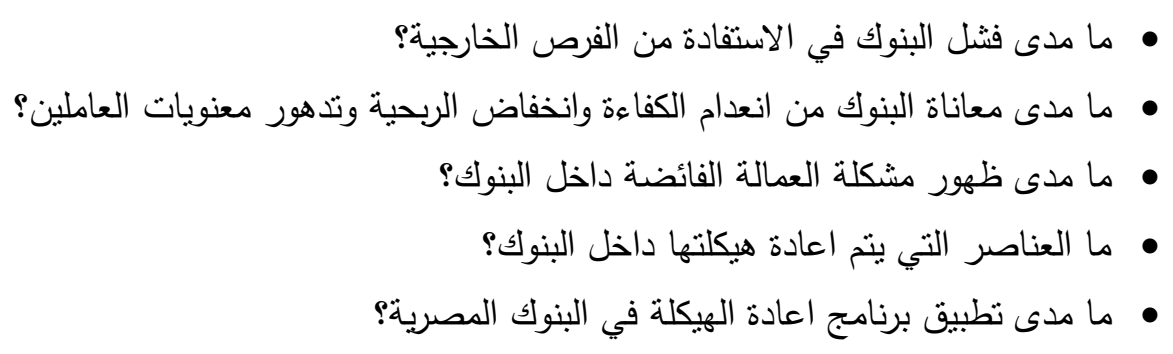

\section{أهما اهنه المهنه}

يتمثل الهدف العام للبحث في إعادة الهيكلة المالية عن طريق إجراء التصحيح اللازم

للهياكل الفنية والاقتصادية والمالية على النحو الذي يمكن المؤسسات المالية من البقاء في دنيا لإداء الاعمال بل والاستمرار بنجاح وتحقيق عائد مناسب. كما يهدف البحث الى تحقيق مجموعة من الأهداف الفرعية الآتية: • إعادة هيكلة العطليات المصرفية للوصول بمستوى الاداء الي المقاييس العالمية.

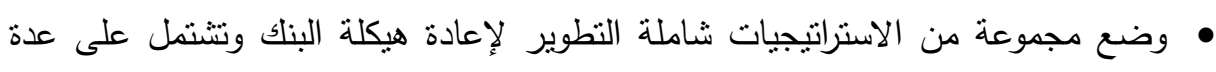

$$
\text { مراحل منها: }
$$

أولاً: تحديد الصعوبات التي تواجه البنك.

ثانياً: وضع البرامج التنفيذية الكفيلة بتحقيق هذه الاهدئ التهاف:

$$
\text { • • إقامة بنية اساسية ذات تقنية حديثة. }
$$

$$
\text { • • • • • نوير شكل البنك وهويته وتحديث فروعه. }
$$

• تغيير الثقافة السائدة بين العاملين وفهم تأثنير عملية التطوير على على العاملين في ظل ثقافتهم

$$
\text { وتاريخهم الوظيفي وقدرتهم على التطوير • }
$$

• المحافظة على منظومة الاداء المنطور بعد تطبيقها.

\section{أهمية المهبه}

تبرز أهمية البحث في الدور الحيوي الذى يؤديه النشاط المصرفي (البنوك) كوسيط مالي على مستوى الاقتصاد القومي ككل، وعلى مستوى هذه المؤسسات المالية. 230

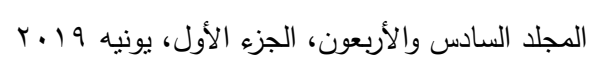


كما نظهر أهمية البحث في دور البنوك كوسيط بين الموارد المتاحة أو المدخرة وأوجه

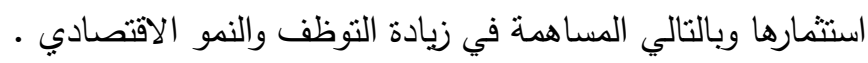

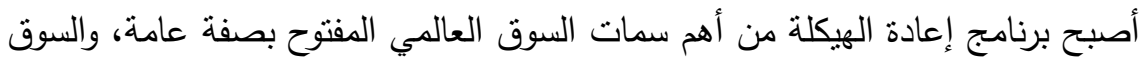
المصري بصفة حاصة .

يعتبر برنامج إعادة الهيكلة أحد الجوانب الهامة في ظل زيادة القدرة التتافسية، والتطورات التكنولوجية المتلاحقة التي أدت الي خروج بعض البنوك من مجال العمل نتيجة لعدم قدرتها على الصمود والفنشل في وضع استراتيجيات تكسبها القدرة على البقاء، وتخفيض التكاليف. وبذلك تظهر أهمية البحث بيان أثز إعادة الهيكلة المالية في البنوك وخاصة البنك الرئيسي للتتمية والائتمان الزراعي "دراسة ميدانية"، على التكاليف، وتحسين مستوى الاداء.

\section{هروغر المهيد}

يعتبر هذا البحث محاولة لتحديد أهم المشكلات التي تؤثز على قدرة المؤسسات المالية في تأدية عملها المصرفي، بهدف صياغة إطار محاسبي مقترح يمكن من خلاله قياس تأثير

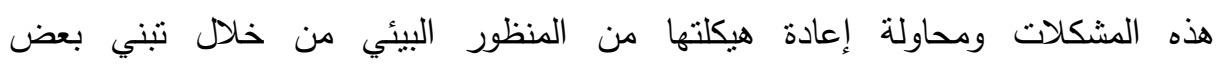
الاستراتيجيات شاملة النطوير وتقوم الدراسة في هذا البحث على اساس الفروض التالية: الفرض الأول: لا تؤثر اعادة الهيكلة المالية على تعظيم الربحية في البنك الرئيسي للتتمية والائتمان الزراعي. وسوف يتم تحليل هذا الفرض "عنصر الربحية" من خلال الفرضين الفرعيين التاليين:

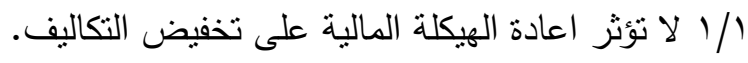

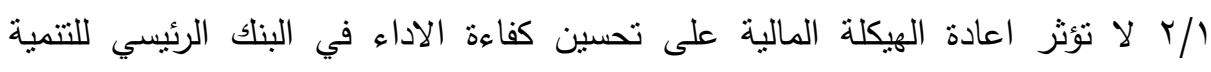

$$
\text { والائتمان الزراعي من المنظور البيئي. }
$$

الفرض الثاني: لا توجد علاقة معنوية بين القيود الرقابية والادارية التي تفرضها القوانين على المؤسسات المالية وضرورة حصولها على العديد من الموافقات للقيام ببرامج التطوير •

$$
\text { المجلد السادس والأربعون، الجزء الأول، يونيه } 19 \text { ـ. }
$$


القرض الثالث: لا نوجد علاقة معنوية بين القرارات السيادية بالدولة ومدي كفاءة عمل هذه المؤسسات المالية في تقديم الخدمة المصرفية بالتقنيات الحديثة. الفرض الرابع: لا توجد علاقة معنوية بين مدي كفاءة العمل في المؤسسات المالية ومنظومة الائتمان والتسويق. الفرض الخامس: لا توجد علاقة معنوية بين الكفاءة الاتناجية وعدم وجود حوافز مادية للعاملين بالمؤسسات المالية.

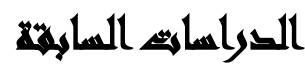

دراسة طارق حسين طاهر (ع ـ . ץ): إستهدفت الدراسة توضيح أثز سياسات إعادة هيكلة العمالة على فعالية أداء العنصر البشري خاصة بعد التحول الي القطاع الخاص، وركزت الدراسة على قطاع الصناعات الغذائية حيث أن هذا القطاع يمس مباشثرة إحتياجات

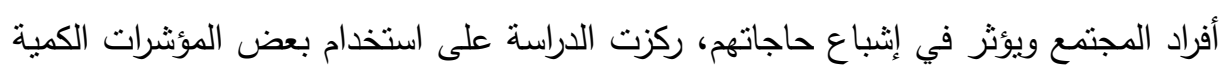

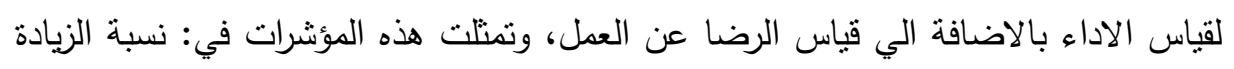

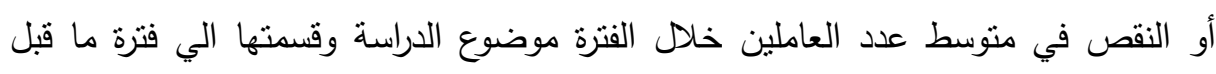
إعادة هيكلة العمالة الي قسمين هما (مؤشرات الانتاجية وتتشمل انتاجية العامل وانتاجية

الاجور - مؤشرات الربحية وتتمل ربحية العامل).

وتوصلت الدراسة الى أن هناك تأثثر واضح لتطبيق سياسة إعادة هيكلة العمالة على الثى

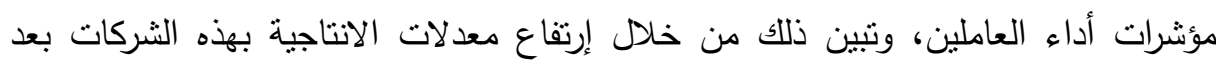

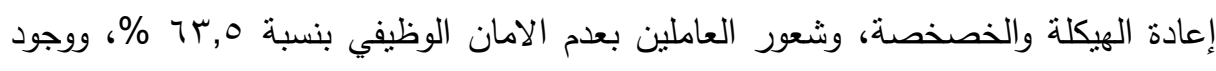

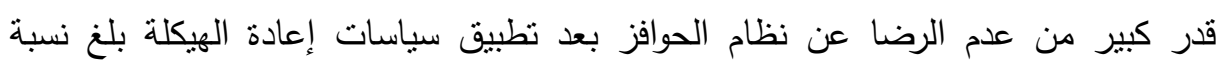

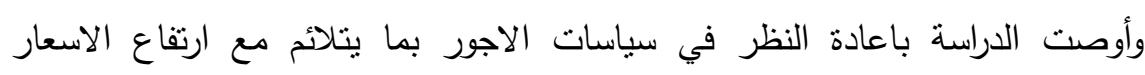

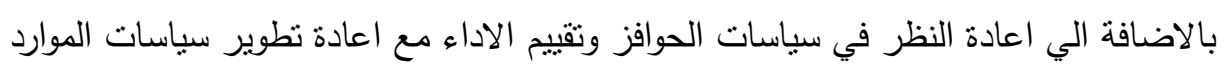

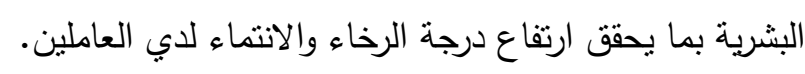




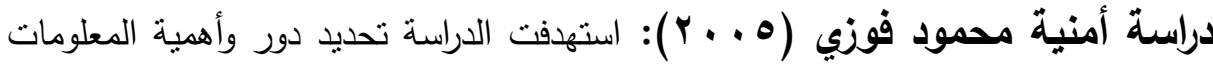
المحاسبية بالنسبة للوحدة الاقتصادية ذاتها، واهميتها لتعزيز القدرة التتافسية من خلال عمليات اعادة الهيكلة المالية للوحدة الاقتصادية. وتتاولت الدراسة ثلاث مجالات في الوحدة الاقتصادية نظهر فيها اهمية المعلومات

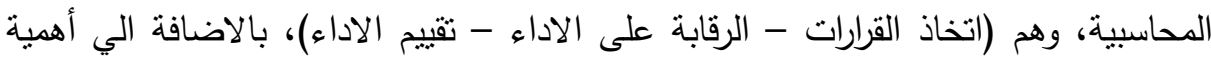
المعلومات المحاسبية في مجال التتافسية، ومنظور الجودة في الوحدات الاقتصادية. وأوضحت الدراسة ألا يقتصر قياس الجودة على الجوانب التي يمكن التعبير عنها في صورة مالية فقط، وانما يجب أن يتضمن القياس مؤشرات غير مالية مثل : مدخل ادارة التكلفة الاستراتيجية، ومدي قدرته على توفير المعلومات، ومن خلال الدراسة التطبيقية في مجال قطاع الدواء في مصر، وباستخدام اسلوب الانحدار المندرج وبرنامج SPSS، توصلت نتائج النتغيل الي وجود ثلاث نماذج يقيم النموذج الثالث للمتغيرات الاتية: (العائد على حقوق لئن الملكية - العائد على المبيعات - العائد على الاصول).

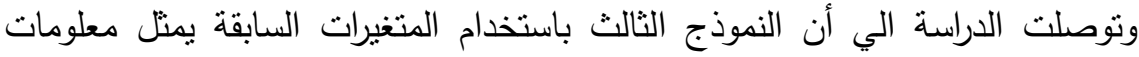
محاسبية، يمكن أن توصل الوحدة المحاسبية الي مدي احتياجها الي عملية اعادة الهيكلة من عدمها، وبالتالي تظهر أهمية المعلومات المحاسبية في اعادة الهيكلة المالية.

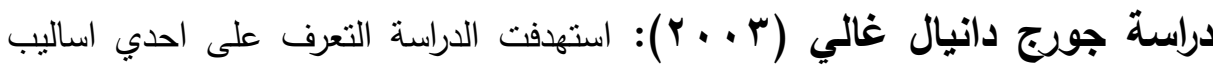
اعادة الهيكلة المالية المتمثلة في الاندماج، ومعرفة المشاكل المحاسبية المترتبة على اندماج

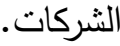

استعرضت الدراسة دوافع الاندماج، والمشاكل المحاسبية المتعلقة باختبار طريقة

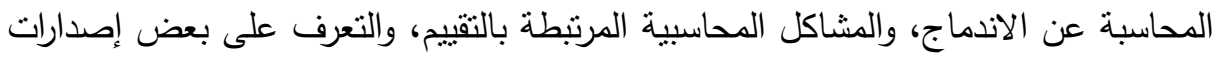
فريق العمل Emerging Issues Task Force (E I T F) المنبثق عن مجلس معايير المحاسبة المالية في الولايات المتحدة الامريكية.

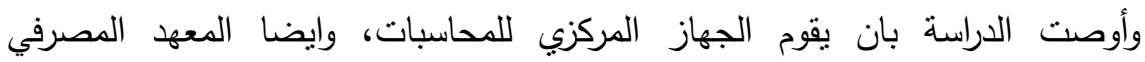
للمحاسبين والمراجعين بتحديث المعايير المحاسبية التي أصدرها بشأن اندماج المشروعات،

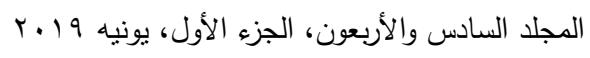


وان تتوصل المنظمات المهنية التي تصدر المعايير المحاسبية الي اتفاق بخصوص تحديد فترة استهلاك الثهرة، ومعالجة الثهرة المالية، وتقييم امكانية استرداد الثهره مع نوضيح الافصاح المرتبط بها.

كما أوضحت الدراسة بضرورة تحديد معايير للتقييم يمكن تطبيقها عند المحاسبة عن التهن الاندماج، حيث يمكن تضييق أوجه اختلاف النتائج المترتبة على اجراء التقييم.

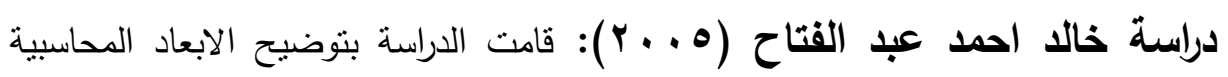
لاعادة هيكلة البنوك من خلا الاعتماد على آلية الدمج، كاحد الادوات التي يتم استخدامها

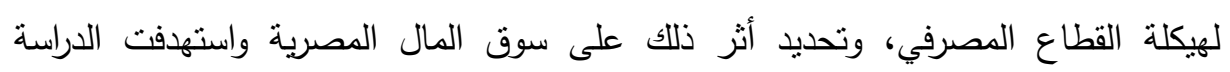
تحديدالاساليب الفنية المستخدمة في اعادة الهيكلة بشكل عام ،والنماذج المستخدمة في اعادة الهرف الهيكلة المصرفية بشكل خاص، كما استهدفت الدراسة تحديد اهم المناهج المحاسبية المستخدمة في عملية تقييم البنوك، واختبار اكثرها ملائمة عند التطبيق، خاصة في ضونه ضواء المشكلات المحاسبية المتعلقة بتقييم الاصول والالتزامات، والمعالجات المقترحة لها.

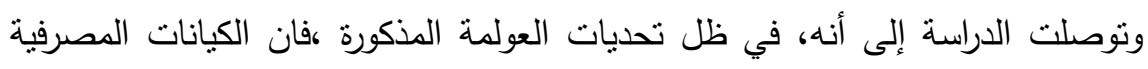
الصغيرة والمتوسطة لن تكون قادرة على امتلاك الملاءة المالية المطلوبة، وكذا حزمة القرارات اللازمة لادارة هذه الملاءة، ومن ثم فان اتجاهات الدمج المصرفي تصبح هنح هي الالية المناسبة

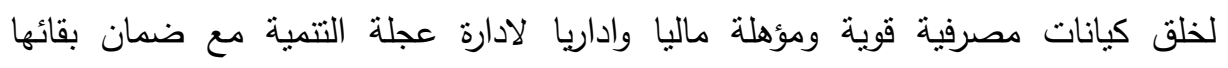
واستمرارها على السلاحة المصرفية. دراسة هالة ابراهيم مهلي عبدالله محجوب (11 ب r): استهدفت الدراسة بتوضيح

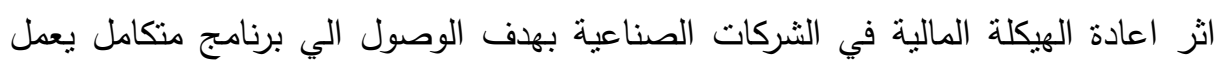
على تخفيض التكاليف، وتحسين كفاءة الاداء، وتعظيم الربحية. وقد اثارت الباحثة الي نظوير العمل المحاسبي لملائمة أهداف اعادة الهيكلة المثالية، مما يؤدي الي رفع كفاءة النظام المحاسبي لكلا الاطراف الداخلية والخارجية ومرحلة النتغيل وتتمنل في التركيز على انشاء قاعدة بيانات تحقق كافة الاهداف والمخرجات النهائية المطلوبة بالاضافة الي التوصل المباشر للاطراف الخارجية والداخلية عن طريق شبكات الانترنت

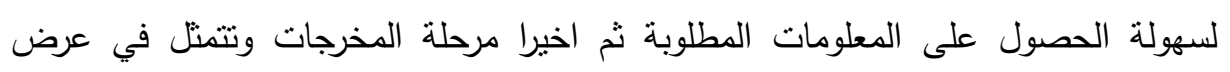


وتحليل المعلومات بحيث يكون هناك مفاهيم رئيسية وتحسينات في التقارير المالية مما يعمل

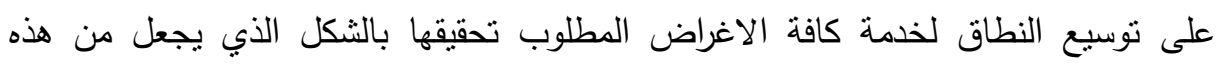
النطوير شكل ملائم لتحقيق أهداف اعادة الهيكلة المالية. وتوصلت الدراسة الي أن اهنمام الادارة العليا بالمفاهيم الحديثة يؤدي الي عدم تأخير

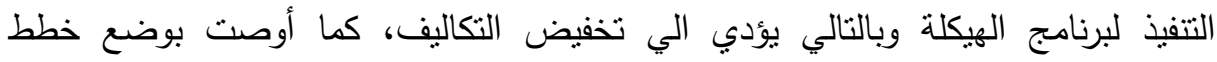

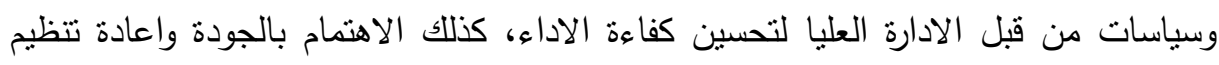

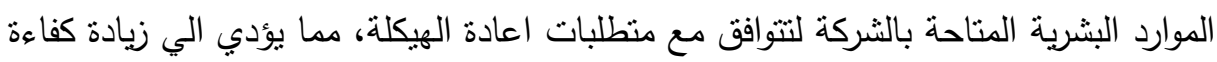
الاداء المرغوب في تحقيقها.

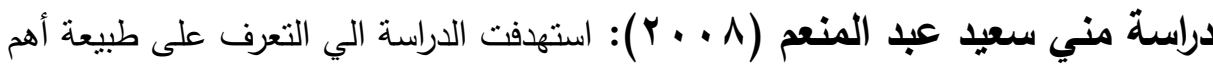
الاساليب المنبعة في اعادة هيكلة شركات قطاع الاعمال العام، وتوسيع قاعدة ملكيتها وتحديد

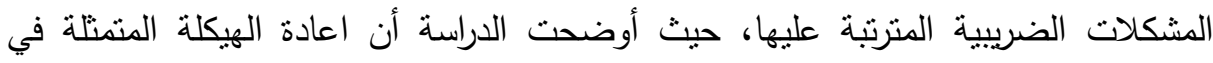
توسيه قاعدة الملكية تعمل على (تحسين النتائج الاقتصادية والمالية للشركات التي يتم خصخصنها - خفض عجز موازنة الدولة الناجم عن دعم الدولة للشركات الخاسرة - استثمار حصيلة بيع حصص الدولة في هذه الثركات في النهوض بالثركات الاخري للتمكن من بيعها

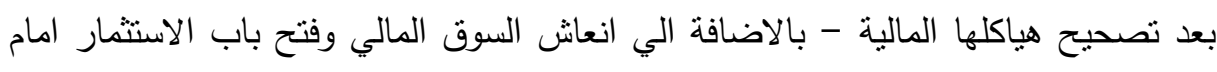

$$
\text { المال الاجنبي). }
$$

ركزت الدراسة على المشكلات الضريبية لاعادة الهيكلة المالية لشركات قطاع الاعمال

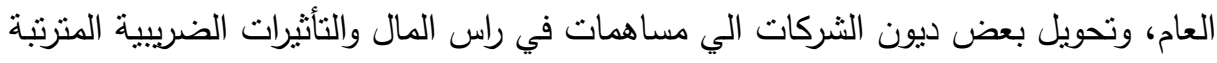
على كل منها. قدمت الدراسة توصيات ومقترحات تعمل على علاج المشكلات الضريبية المترتبة على

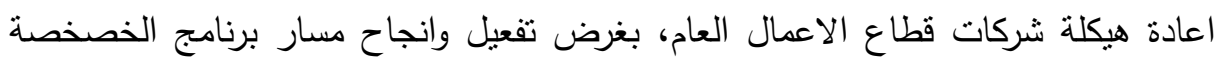

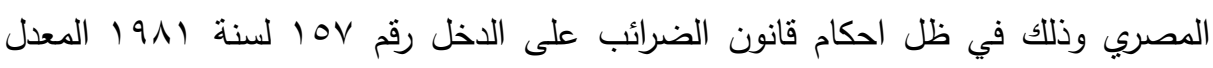

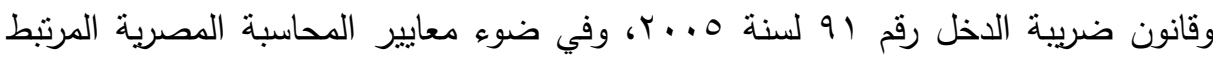




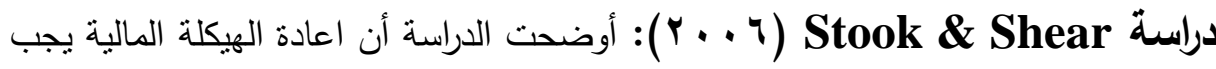

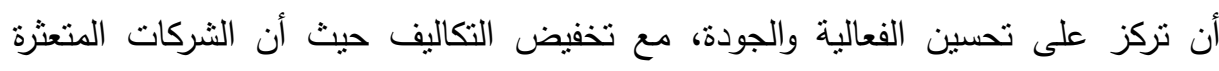

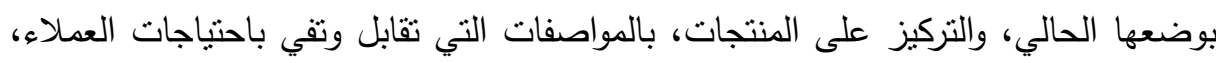
مما بعني تحقيق المزايا التنافسية.

وأوضحت الدراسة أن هناك نوعين من الكنتجات العائدة تتضمن (التي يمكن مراقبتها -

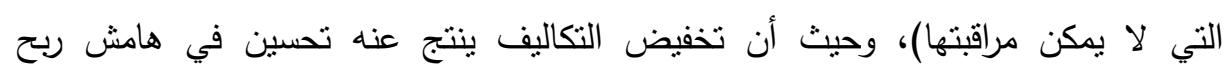

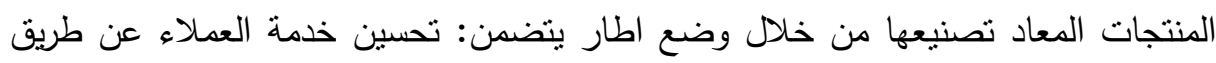

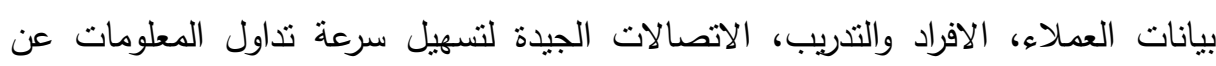

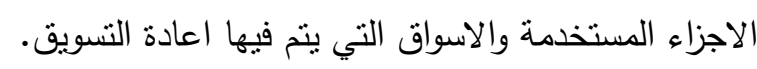

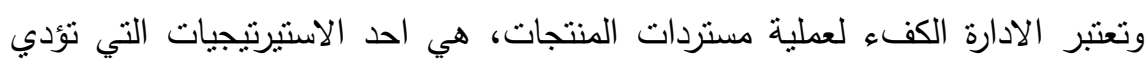

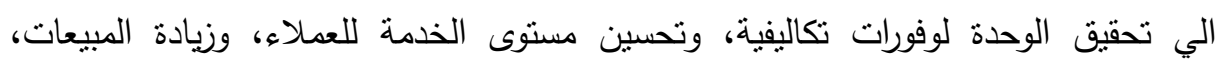
والنصيب السوقي للمنتجات، مما يعني تحقيق الثركة لمزايا تنافسية.

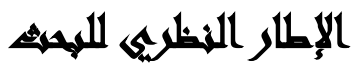

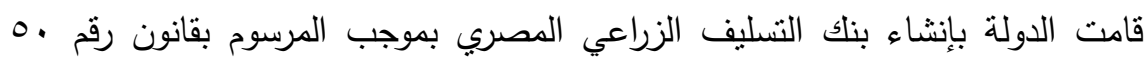

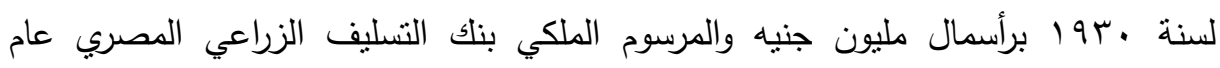

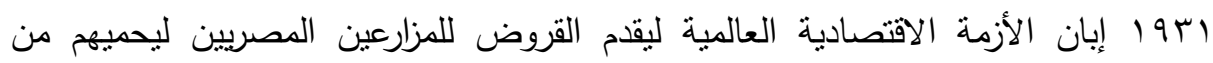

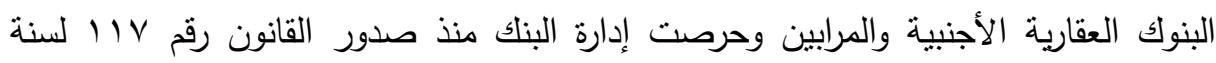

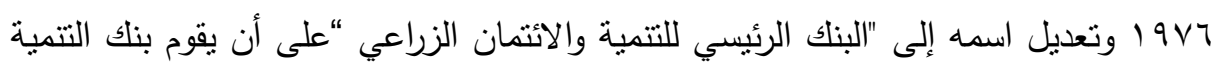

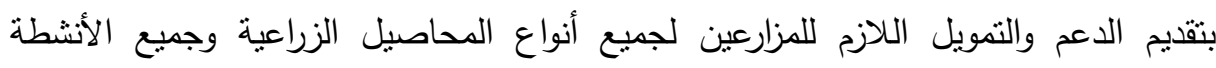

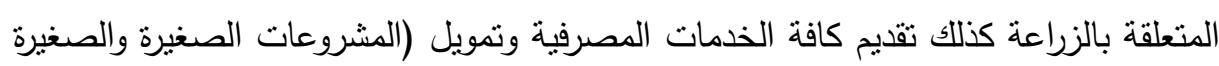

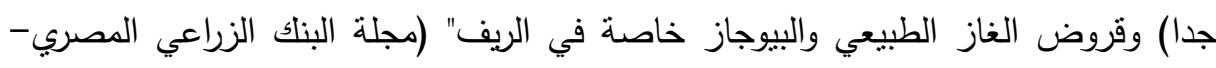

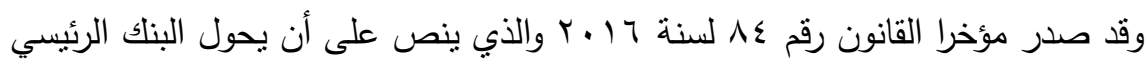

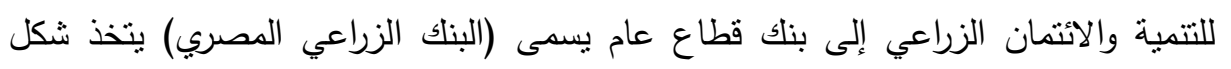
236

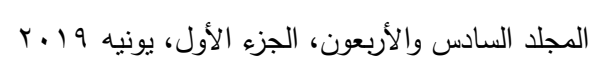


شركة مساهمة مصرية مملوك رأس مالها بالكامل للاولة، ويكون له الثخصية الاعتبارية المستقلة، ومركزه الرئيسي مدينة القاهرة الكبرى، وتؤول له كافة حقوق البنك الرئيسي للتنمية والايتمان الزراعي ويتحمل بالتزاماته.

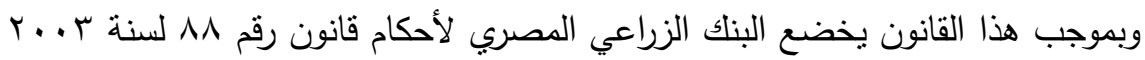

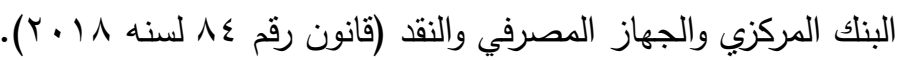
ويهدف البنك الزراعي المصري إلى نوفير التمويل اللازم لمختلف أنواع أنشطة التتمية الزراعية والريفية وفقا للنظم المصرفية المعدول بها فى إطار السياسة العامة للدولة. ويعد البنك الزراعي المصري من أهم المؤسسات النتموية للنشاط الزراعي في مصر فهو فئه

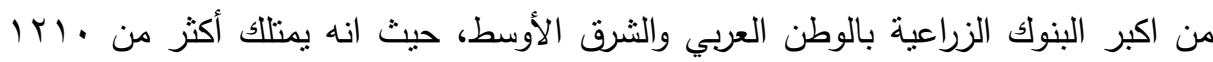

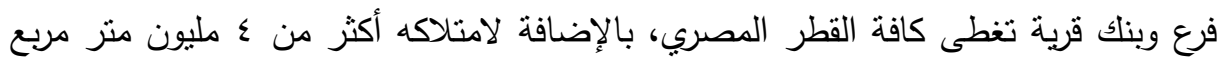

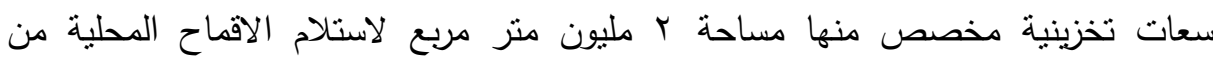
المزارعين كذللك يبلغ عدد الثون بوج شونة لاى البنك منتشرة بأنحاء الجمهورية.

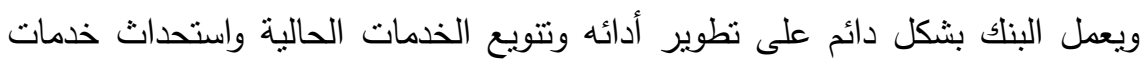
جديدة ليتواكب مع متطلبات المراحل المتتالية وتقديم الخدمات المالية والتمويلية وغيرها من

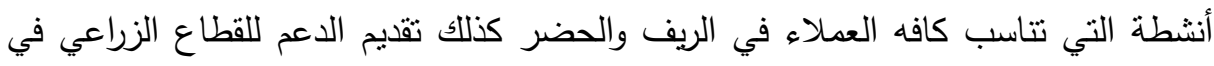

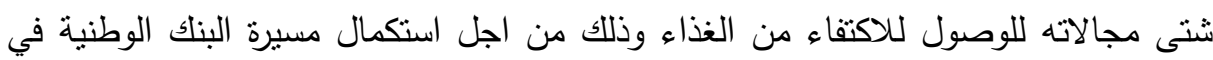

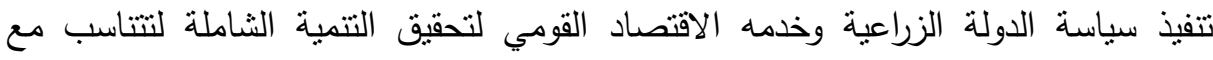
المتغيرات الاقتصادية. يطبق البنك الأسس والمعايير الدولية في إطار قواعد الإفصاح والثفافية وتثوم إدارة

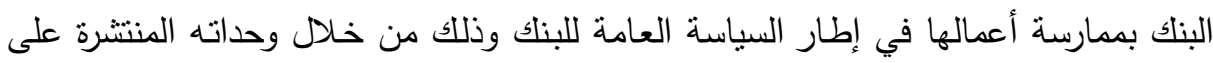
مستوى المحافظات والمدن والقرى (مجلة البنك الزراعي المصري الثهرية)

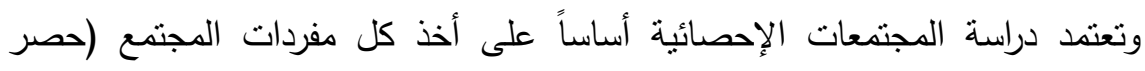

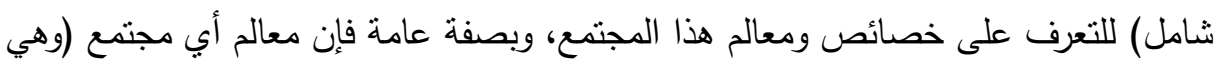

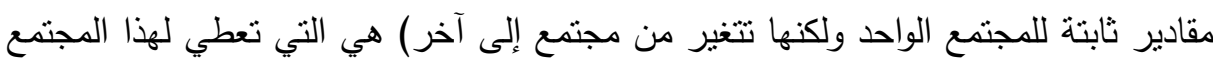

$$
\text { المجلد السادس والأربعون، الجزء الأول، يونيه } 19 \text { ـ. }
$$


صفاته دون غيره؛ ونظراً لوجود صعوبات كثثرة تحول دون دراسة جميع مفردات مجتمع الرات

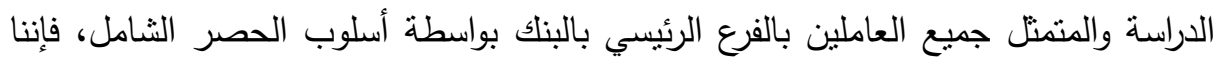

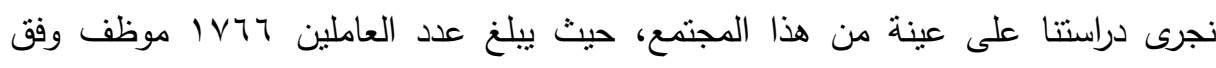

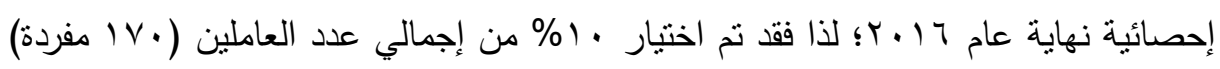

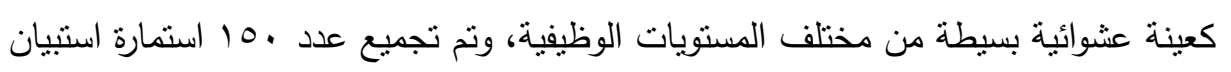

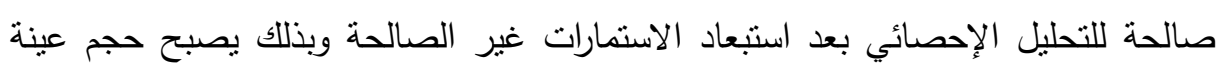
الدراسة الميدانية ـ 10 - مفردة.

\section{إجباءاهي المهيد}

تصميم قائمة الاستبيان: تم تصميم قائمة استبيان تضمنت مجموعة من العبارات تقيس

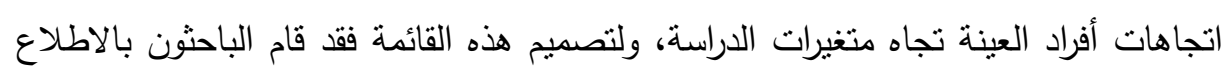
على عديد من الدراسات السابقة في مجال موضوع الدراسة، وانتهت إلى إعداد استمارة استبيان تضمنت بعض المقاييس التي تعكس متغيرات الدراسة.

وقد صممت الاستمارة بطريقة "ليكرت" على مقياس خماسي الاتجاه حيث كان لكل إجابة لتراسية

\begin{tabular}{|c|c|c|c|c|c|}
\hline & & & & \multicolumn{2}{|c|}{ وزن مرجح وذلك كما يلى: } \\
\hline قأوافيلة جدرجة & بدرجة قليلة & أوافق بلرجة & بدرجة كبيرة & كبيرة جداً & درجة المواققة \\
\hline 1 & r & $r$ & $\varepsilon$ & 0 & الوزن المرجح \\
\hline
\end{tabular}

أساليب المعالجة الإحصائية: قام الباحثون باستخدام الحاسب الآلي على حزم البرامج الإحصائية SPS ver.20، وذللك لتحليل البيانات التي نم الحصول عليها من خلال استمارة الاستبيان، وذلك باستخدام الأساليب التالية: - قياس ثبات استمارة الاستبيان باستخدام معامل "كرونباخ ألفا".

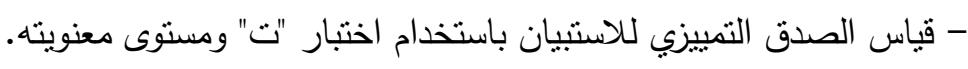
- مقاييس النتتت والنزعة المركزية لقياس اتجاهات عينة البحث وتحليل النتائج. - تحليل التباين لتحديد جوهرية العلاقة بين المتغيرات والظاهرة محل البحث. 
- معامل ارتباط "بيرسون" لبحث العلاقات الارتباطية لمتغيرات البحث. - الانحدار الخطي البسيط للتوصل إلى تأثثر المتغيرات المستقلة على المتغيرات التابعة.

\section{الخصائص الديموجرافية لعينة الدراسة:}

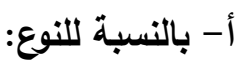

جدول (1): التكرارات والنسب المئوية لعينة الدراسة فيما يخص النوع لئه

\begin{tabular}{|c|c|c|c|}
\hline النسبة المئوية & التكرار & التوزيع & البيان \\
\hline$\% \leftleftarrows$ & 7. & ذكر & \multirow{2}{*}{ النوع } \\
\hline$\% 7$. & 9 . & آنتي & \\
\hline$\% 1 \ldots$ & 10. & - & الإجمالى \\
\hline
\end{tabular}

يعكس الجدول السابق ثقة عالية في النتائج لثمول العينة لكلا النوعين. ب - بالنسبة للمستوى التعليمي:

\begin{tabular}{|c|c|c|c|}
\hline النسبة المئوية & التكرار & التوزيع & البيان \\
\hline$\% \vee, 0$ & $1 \wedge$ & دراسات عليا & \multirow{3}{*}{ التعليميتي } \\
\hline$\% 7$. & 9. & مؤهل جامعى & \\
\hline$\%$ \%r,o & Or & مؤهل أقل من المتوسط & \\
\hline$\% 1 \ldots$ & 10. & - & الإجمالي \\
\hline
\end{tabular}

يتضح من الجدول السابق احتواء العينة على مستويات تعليمية متباينة، ويعكس هذا نقة عالية في النتائج المتحصل علنها لارتفاع المستوى التعليمي لمفردات العينة. ج- بالنسبة للمستوى الوظيفي: جدول (ץ): التكرارات والنسب المئوية لعينة الدراسة فيما يخص المستوى الوظيفي

\begin{tabular}{|c|c|c|c|}
\hline النسبة المئوية & التكرار & التوزيع & البيان \\
\hline$\% 1$. & 10 & إدارة عليا & \multirow{3}{*}{ الوظيفي } \\
\hline$\%$ \%. & $\varepsilon 0$ & إدارة وسطى & \\
\hline$\% 7$. & 9. & أدارة تتفيذية & \\
\hline$\% 1 \ldots$ & 10. & - & الإجمالى \\
\hline
\end{tabular}

يتضح من الجدول السابق احتواء العينة على مستويات وظيفية متعددة، ويعكس هذا نقة عالية في النتائج المتحصل عليها لثمول العينة جميع المستويات الوظيفية على اختلاف دوافعهم وإدراكهم لموضوع البحث.

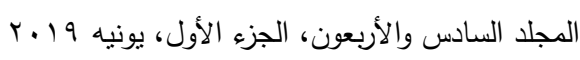




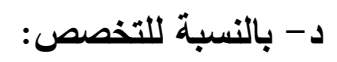
جدول (؛ ): التكرارات والنسب المئوية لعينة الدراسة فيما يخص التخصص التصد

\begin{tabular}{|c|c|c|c|}
\hline النسبة المئوية & التكرار & التوزيع & البيان \\
\hline$\% \varepsilon$ & 7. & شئون إدارية وموارد بشرية & \multirow{6}{*}{ التخصص } \\
\hline$\%$ \%. & $\leqslant 0$ & شئون مالية & \\
\hline$\% 1$. & 10 & شئون فنية & \\
\hline$\% \wedge$ & ir & شئون قانونية & \\
\hline$\% \mathrm{~V}$ & 11 & شُئون تجارية & \\
\hline$\% 0$ & $\mathrm{~V}$ & شُئون عامة & \\
\hline$\% 1 \ldots$ & 10 & - & الإجمالى \\
\hline
\end{tabular}

يتضح من الجدول السابق شمول العينة لمختلف التخصصات، وأنها شملت آراء واتجاهات جميع التخصصات على اختلاف ميولهم واتجاهاتهم، مما يسهم في صحة الاعنماد على نتائج الدراسة.

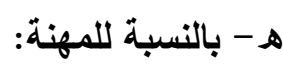

\begin{tabular}{|c|c|c|c|}
\hline النسبة المئوية & التكرار & والنسب المتويها لعينه الدراسه & البيان (0) \\
\hline$\% \backslash r$ & 11 & أقل من 0 سنوات & \multirow{5}{*}{ 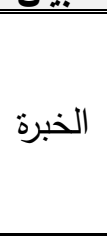 } \\
\hline$\%$ \%r & 0. & من 0 - أقل من • ا سنوات & \\
\hline$\%$ Y० & $r V$ & من · 1 - آقل من 10 سنوات & \\
\hline$\% r$. & $r$. & من 10 - آقل من ·r سنة & \\
\hline$\% 1$. & 10 & r r سنة فأكثر & \\
\hline$\% 1 \ldots$ & 10. & - & الإجمالى \\
\hline
\end{tabular}

يتضح من الجدول السابق شمول العينة لمستويات خبرة متعددة، مما يسهم في صحة الاعتماد على نتائج الدراسة لاختلاف الآراء والتوجهات وفقاً لمدة الخبرة.

\section{قياس ثبات وصدق الاستبيان}

قياس ثبات الاستبيان: نم قياس ثبات اتجاه عينة الدراسة نحو المقاييس المستخدمة وذلك

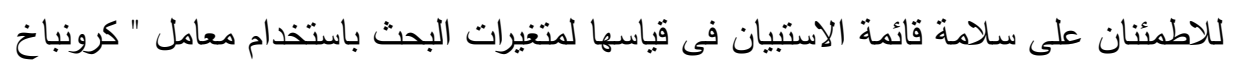
ألفا". 
جدول (†): معامل الثبات لمتغيرات الدراسة

\begin{tabular}{|c|c|c|}
\hline معامل a & نوع المتغير & المتغير \\
\hline$\% \circ \wedge, 0$ & مستقل & إعادة الهيكلة المالية \\
\hline$\% \circ Y, Y$ & تابع & الربحية \\
\hline$\% 79,9$ & تابع & تخفيض التكاليف \\
\hline$\% \vee \vee, 1$ & تابع & كفاءة الأداء \\
\hline$\% \vee \varepsilon, \vee$ & 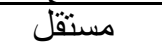 & القيود الرقابية والإدارية \\
\hline$\% 7,7$ & تابع & الموافقات \\
\hline$\% 79,0$ & مستقل & القرارات السيادية \\
\hline$\% \wedge r, 1$ & تابع & كفاعة الخدمة \\
\hline$\% \vee \cdot, 9$ & مستقل & كفاءة العمل \\
\hline$\% 77,0$ & تابع & منظومة الائتمان والتنسويق \\
\hline$\% \wedge \cdot, r$ & مستقل & الكفاءة الإنتاجية \\
\hline$\% 71, \varepsilon$ & تابع & الحوافز \\
\hline
\end{tabular}

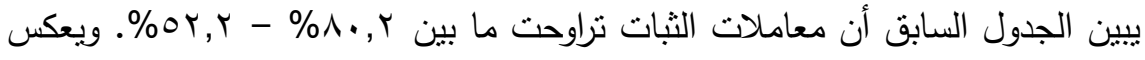

ذلك ثبات جيد للاستبيان.

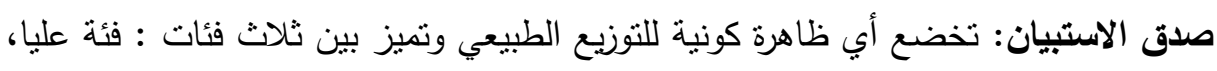

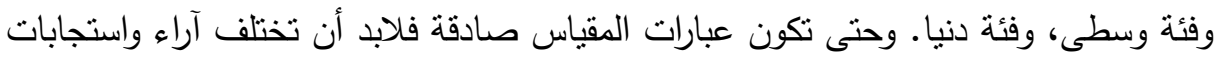

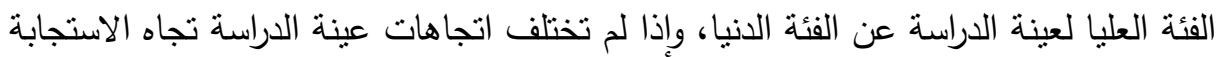
لعبارة ما، تصبح تللك العبارة غير صادقة حيث أنها لم تميز بين هاتان الفئتان ويلزم حذفها من

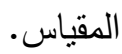

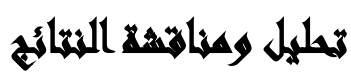

تحليل نتائج محور إعادة الهيكلة المالية: قام البحث باستخدام حزم البرامج الإحصائية

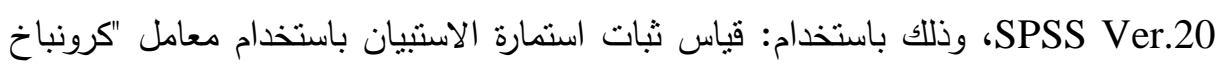

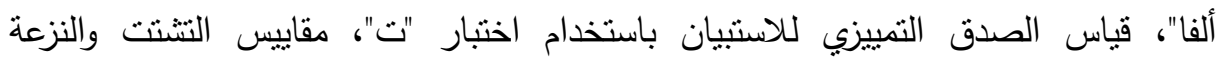
المركزية، تحليل التباين، معامل ارتباط "بيرسون"، الانحدار الخطي البسيط وقد تبين أن: 
أميرة محمد محمد المعناوي وآخرون

\begin{tabular}{|c|c|c|c|}
\hline الأهميبة & المتوسط & العبارات & العبارة \\
\hline r & $\varepsilon, 19$ & يتعين توافر الأسباب والعوامل التي تؤدي إلى نجاح تطبيق إعادة & 1 \\
\hline r & $\varepsilon, r_{0}$ & 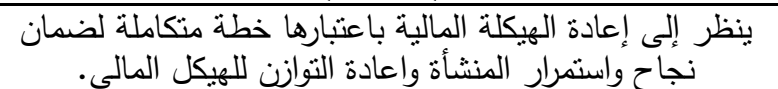 & r \\
\hline 1 & $\varepsilon, r_{0}$ & تؤدي إعادة الهيكلة المالية إلى تحسين موقف السيولة بالمنشأة. & $r$ \\
\hline
\end{tabular}

تحليل نتائج محور تعظيم الربحية: من نتائج الدراسة الميدانية لمحور تعظيم الربحية نجد اتفاق عينة الدراسة على أهمية إعادة الهيكلة المالية لتعظيم الربحية بالبنك الزراعي

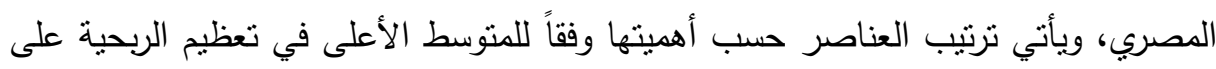

\begin{tabular}{|c|c|c|c|}
\hline الأزميبة & المتوسط & العبارات & العبارة \\
\hline 1 & $\varepsilon, Y\}$ & 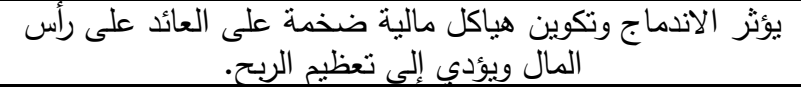 & 1 \\
\hline$r$ & $\varepsilon, Y_{O}$ & 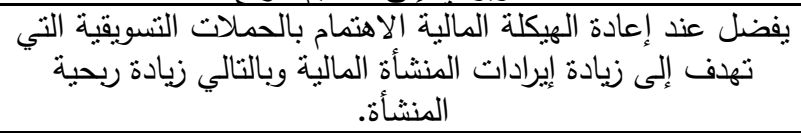 & $r$ \\
\hline 1 & $\varepsilon, \cdot V$ & 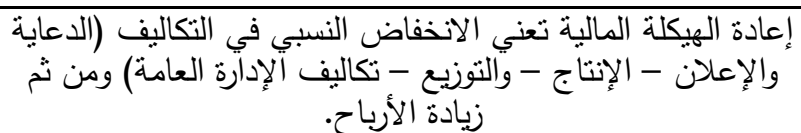 & $r$ \\
\hline$r$ & $\varepsilon, Y T$ & 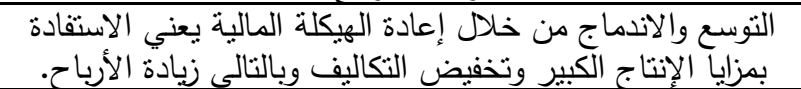 & $\varepsilon$ \\
\hline 0 & $\varepsilon, r$. & 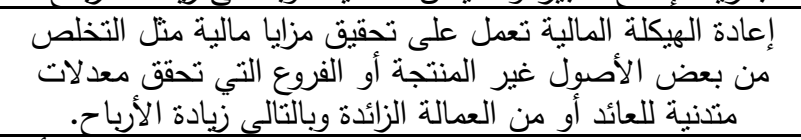 & 0 \\
\hline$\varepsilon$ & $\Sigma, Y Y$ & 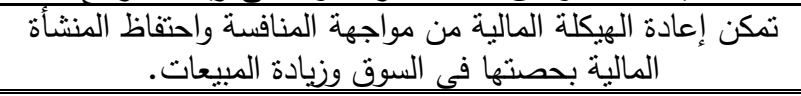 & 7 \\
\hline
\end{tabular}

تحليل نتائج محور تخفيض التكاليف: من نتائج الدراسة الميدانية لدحور تخفيض التكاليف نجد أن المتوسط الحسابي لجميع عبارات المحور أكثز من ب درجات (المتوسط

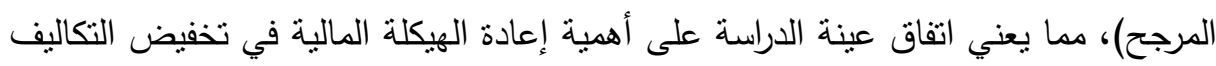
بالبنك الزراعي المصري، وعليه فإن: ليطي 
مجلة العلوم البيئية

معهد الدراسات والبحوث البيئية - جامعة عين شمس لئه

\begin{tabular}{|c|c|c|c|}
\hline الأرثيبة & المتوسط & العبارات & العبارة \\
\hline r & $\varepsilon, Y T$ & 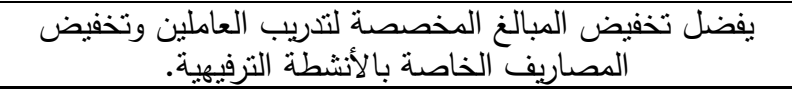 & 1 \\
\hline$\varepsilon$ & $\varepsilon, \cdot T$ & 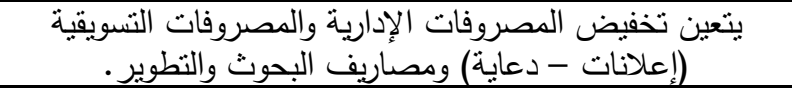 & $r$ \\
\hline 0 & $r, \wedge \wedge$ & 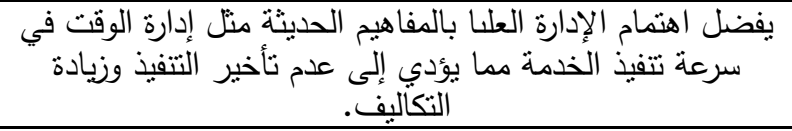 & $r$ \\
\hline r & $\varepsilon, Y_{\tau}$ & 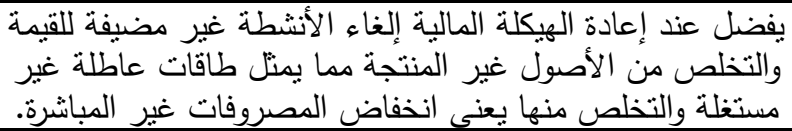 & $\varepsilon$ \\
\hline 1 & $\varepsilon, Y \wedge$ & تؤدي إعادة الهيكلة المالية إلى إجراء تغيرات في تشكيلة الخدمات الإنتات & 0 \\
\hline
\end{tabular}

تحليل نتائج محور كفاءة الأداء: من نتائج الدراسة المبدانية نجد اتفاق عبنة الدراسة

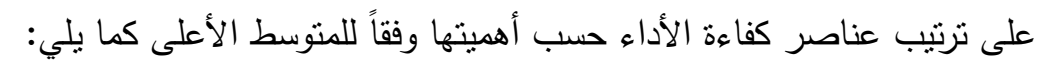

\begin{tabular}{|c|c|c|c|}
\hline ترأليب & المتو & العبارات & العبارة \\
\hline r & $\varepsilon, r q$ & يتعين إعادة تتظيم الموارد البشرية المتاحة بالمنشأة لتتوافق مع متطلبات المياتة & 1 \\
\hline 1 & $\varepsilon, \Gamma$. & 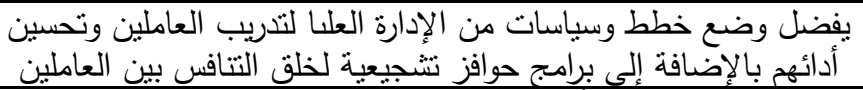 & r \\
\hline$r$ & $r, Y V$ & 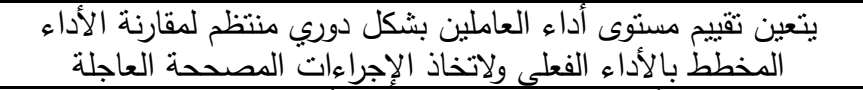 & $r$ \\
\hline 0 & $\varepsilon, r Y$ & 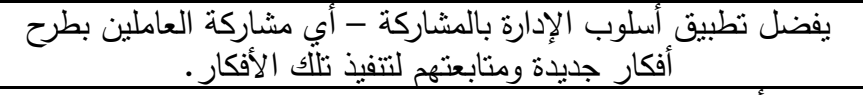 & $\varepsilon$ \\
\hline$\varepsilon$ & $\varepsilon, r \tau$ & 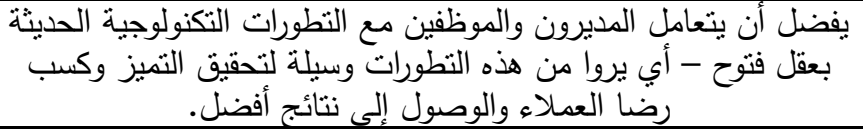 & 0 \\
\hline V & $\varepsilon, 10$ & 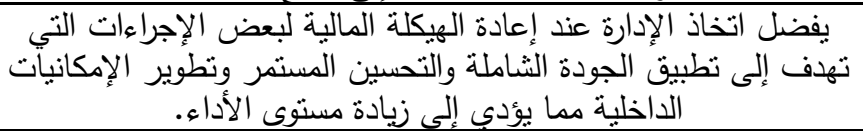 & 7 \\
\hline 7 & $\varepsilon, Y$. & 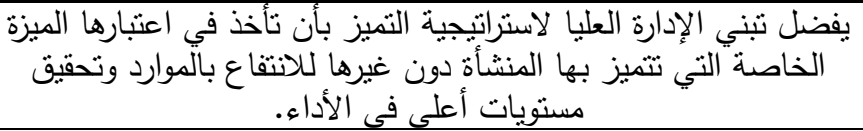 & $V$ \\
\hline
\end{tabular}


تحليل نتائج محور القيود الرقابية والإدارية: من نتائج الدراسة الميدانية لمحور القيود

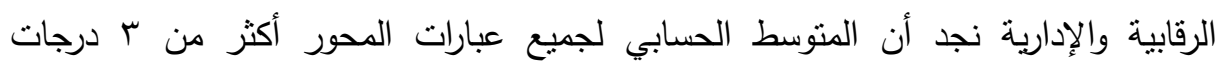
(المتوسط المرجح)، مما يعني اتفاق عينة الدراسة على ترنيب عناصر القيود الرقابية والإدارية

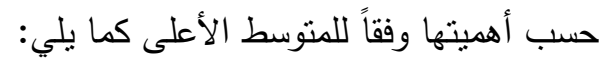

\begin{tabular}{|c|c|c|c|}
\hline الأرهيبة & المتوسط & العبارات & العبارة \\
\hline 1 & $r, 0$. & حدوث تعدي بقصد الإساءة لنظام العمل ويؤدي إلى حدوث خسائر & 1 \\
\hline$\varepsilon$ & r, r & حدوثُ احتبال (متل الاحتبال في المخالفات الائتمانية) & $r$ \\
\hline$\overline{9}$ & r,ir & حدوث سرقة، ابتزاز ، اختلاس & $\bar{r}$ \\
\hline 7 & $r, Y$, & حدوث إتلاف في الأصول و أو سوء في تخصيص الأصول & $\varepsilon$ \\
\hline 1. & $r, 11$ & حدوث تزوير & 0 \\
\hline 11 & $r, 11$ & حدوث سرقة (ثيكات، ملفات، حسابات عملاء) & 7 \\
\hline r & $r, r \cdot$ & تلقي رشاوى والعمولات غير قانونية & $\mathrm{v}$ \\
\hline$\Lambda$ & $r, 1 \wedge$ & إطلاق شائعات داخل البنكا & $\Lambda$ \\
\hline Ir & $r, .9$ & سوء استخدام السلطات & 9 \\
\hline $\mathrm{v}$ & $r, 19$ & استيلاء على حسابات العملاء & 1. \\
\hline o & r, r & حدوث خسائر نتيجة لكوارث طييعية (زلزال/ سيولة/ أوبئة) & 11 \\
\hline$r$ & $r, r q$ & حدوث خسائر بشرية من مصادر خارجية (إرهاب/ تخرب عمدي) & Ir \\
\hline
\end{tabular}

تحليل نتائج محور الموافقات للقيام ببرامج التطوير: نتائج الدراسة الميدانية لمحور الموافقات للقيام ببرامج النطويراثبت أن اتفاق عينة الدراسة على نرتيب عناصر الموافقات للقيام ببرامج التطوير حسب أهميتها وفقاً للمتوسط الأعلى كما يلي:

\begin{tabular}{|c|c|c|c|}
\hline الأهميبة & المتوسط & العبارات & العبارة \\
\hline$r$ & r,qV & 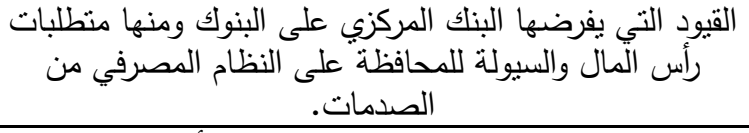 & 1 \\
\hline 1 & $\uparrow, १ \curlywedge$ & 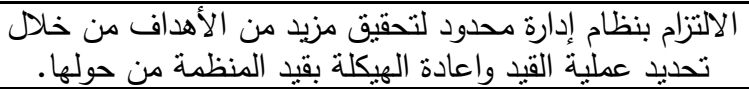 & $r$ \\
\hline
\end{tabular}

تحليل نتائج محور القرارات السيادية: نتائج الدراسة الميدانية لمحور القرارات السيادية نجد اتفاق عينة الدراسة على ترنيب عناصر القرارات السيادية حسب أهيتها وفقاً للمنوسط

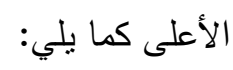


مجلة العلوم البيئية

معهد الدراسات والبحوث البيئية - جامعة عين شمس له

\begin{tabular}{|c|c|c|c|}
\hline ترتيبة & المتوسط & العبارات & العبارة \\
\hline$\varepsilon$ & $r, 0 \leqslant$ & القرارات السيادية بالدولة ومدى كفاءة عمل هذية الخدمات المؤسسات المالية & 1 \\
\hline$r$ & $r, \tau$. & 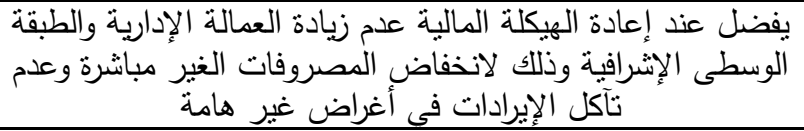 & r \\
\hline 1 & $\varepsilon, 17$ & 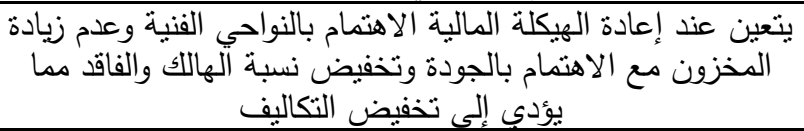 & $r$ \\
\hline r & $\varepsilon, 19$ & يفضل اهتمام الإدارة بعدم تأجيل المديونيات المستحقة على المنشأة & $\varepsilon$ \\
\hline
\end{tabular}

تحليل نتائج محور كفاءة الخدمة المصرفية: من نتائج الدراسة الميدانية لمحور كفاءة الخدمة المصرفية نجد أن المتوسط الحسابي لجميع عبارات المحور أكثر من ب درجات

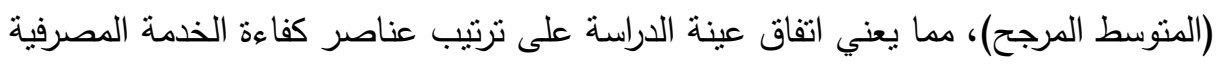

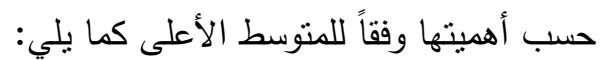

\begin{tabular}{|c|c|c|c|}
\hline الأرميبة & المتوسط & 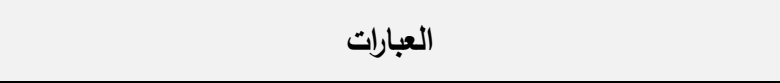 & 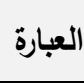 \\
\hline 1 & $r, 0$. & سرقة ممتلكات البنك من طرف خارجي. & 1 \\
\hline 1. & r,乏) & تزوير من طرف خارجي & $r$ \\
\hline 11 & ґ,乏. & سرقة للشيكات أو النقدية من طرف خارجي & r \\
\hline 10 & $r, r \leq$ & سرقة معلومات وبيانات & $\varepsilon$ \\
\hline 9 & r, $\leqslant$ r & اختراق نظم المعلومات من طرف خارجي & 0 \\
\hline 7 & $r, \Sigma V$ & خسائر نتيجة لسوء الاتصالات & 7 \\
\hline $\mathrm{V}$ & r, ¿० & خلل في أعمال الصيانة وتحمل البيانات & $\mathrm{V}$ \\
\hline r & $\Gamma, \Sigma \wedge$ & أخطاء تأخير في تتفيذ عمليات التشاول والبيع والثراء مع الأطراف & $\wedge$ \\
\hline $1 \leq$ & r, tru & أخطاء في تحديد المسئوليات والاختصاصات & 9 \\
\hline Ir & $r, r q$ & خسائر نتيجة لعدم الفصل في الاختصاصات & 1. \\
\hline$\varepsilon$ & $r, \leqslant V$ & حدوث أخطاء محاسبية & 11 \\
\hline 0 & $r, \Sigma V$ & أخطاء في إدارة أدوات الضمان (مثل الغطاء التأمينى) & ir \\
\hline r & $r, \Sigma \Lambda$ & حدوث أخطاء في صيانة الييانات المرجعية & 14 \\
\hline$\wedge$ & $r, \Sigma T$ & تأخير و /أو عدم التزام في تقديم التقارير الإلزامبة (مثل تقارير البنك & $1 \varepsilon$ \\
\hline $1 T$ & $r, r \wedge$ & حدوث أخطاء في أذون العملاء (الصرف والإيداع) & 10 \\
\hline 17 & $r, 1 r$ & عدم الالتزام بوجود عبارات إخلاء مسئولة البنك & 17 \\
\hline
\end{tabular}

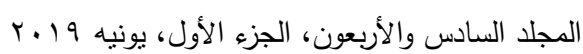


تحليل نتائج محور كفاءة العمل:من نتائج الدراسة الميدانية لمحور كفاءة العمل نجد اتفاق عينة الدراسة على ترتيب عناصر كفاءة العمل حسب أهميتها وفقاً للمتوسط الأعلى كما

\begin{tabular}{|c|c|c|c|}
\hline الأهمبية & المتوسط & العبارات & العبارة \\
\hline r & 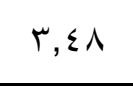 & مدى كفاءة العمل في المؤسسات المالية ومنظومة الائتمان & 1 \\
\hline 0 & $\Gamma, \varepsilon \vee$ & ضباع للمستتدات القانونية & r \\
\hline 7 & $r, r q$ & آخطاء عدم استكمال للبيانات و /آو المستتدات & $\Gamma$ \\
\hline$\Lambda$ & $r, r v$ & السماح باختراق أو الوصول لملفات وحسابات العملاء & $\varepsilon$ \\
\hline 9 & r, ro & أخطاء في تسجيل حسابات العملاء & 0 \\
\hline $\mathrm{V}$ & $r, \mu q$ & إهمال/ تلف في الأصول الخاصة بالعملاء & 7 \\
\hline$r$ & $r, q$. & حدوث أخطاء من أطراف أخرى غير العملاء & $\mathrm{V}$ \\
\hline 1 . & r, ז, & حدوث نزاع مع أطراف أخرى غير العملاء & $\Lambda$ \\
\hline$\varepsilon$ & $\Gamma, \Sigma V$ & نزاع مع الموردين الخارجيين والبائعين & 9 \\
\hline 11 & r,Y r & مخالفات في تطبيق السياسات العامة المنظمة للعمل & 1. \\
\hline 1 & $\varepsilon, 1 \leq$ & عدم ملائية السياسات العامة للتطبيق العملى بالبنانك & 11 \\
\hline
\end{tabular}

تحليل نتائج محور منظومة الائتمان والتسويق: نتائج الدراسة الميدانية لمحور منظومة الائتمان والتسويق نتج عنها اتفاق عينة الدراسة على ترتيب عناصر منظومة الائتمان

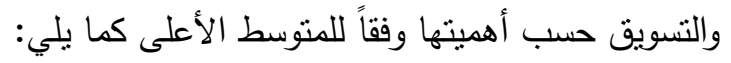

\begin{tabular}{|c|c|c|c|}
\hline ترتيب الأهمية & المتوسط & (العبارات & العبارة \\
\hline 7 & r,Tr & حدوث خلل/ تلف في المكونات المادية & 1 \\
\hline 1 & $\Gamma, 77$ & حدوث خلل/ تلف في آجهزةالصراف الآلى & r \\
\hline $\bar{V}$ & $\overline{r, \mu}$ & حدوث خلل/ تلف في الـ (البرادج والتطبيقات) & $\Gamma$ \\
\hline r & $\Gamma, \Gamma \wedge$ & حدوث خلل/ تلف في منظومة البنك & $\varepsilon$ \\
\hline$\varepsilon$ & $\Gamma, \mu \nu$ & حدوث خلل في الاتصالات & 0 \\
\hline r & $\Gamma, \varepsilon \vee$ & خلل في الخدمات الخارجية & 7 \\
\hline 0 & r, ro & أخطاء في إدخال البيانات & $\mathrm{V}$ \\
\hline
\end{tabular}

تحليل نتائج محور الكفاءة الإنتاجية: نتائج الدراسة الميدانية لمحور الكفاءة الإنتاجية

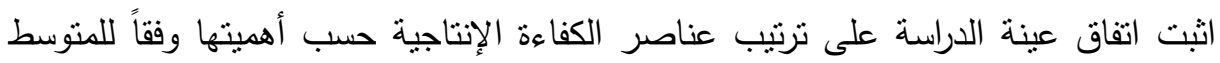

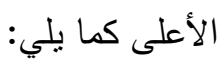


مجلة العلوم البيئية

معهد الدراسات والبحوث البيئية - جامعة عين شمس لبهن

\begin{tabular}{|c|c|c|c|}
\hline الأهمبية & المتوسط & العبارات & العبارة \\
\hline 1 & $\varepsilon, \cdot V$ & الكفاءة الإنتاجية وعدم وجود حوالمواتز مادية للعاملين & 1 \\
\hline 1. & $\Gamma, \Gamma \varepsilon$ & حدوث انتهاك لسرية الحسابات & $\bar{T}$ \\
\hline T乏 & $r, r \wedge$ & حدوث انتهاك للإرشادات ونظ العمل (التعلمات) & $\Gamma$ \\
\hline TY & $\Gamma, \mu$. & عدم الالتزام بمنطلبات الإفصاح (منل نموذج اعرف عميلك) & $\varepsilon$ \\
\hline 7 & $\Gamma, \varepsilon \Gamma$ & حدوث انتهاك للإفصاح لعميل التجزئة & 0 \\
\hline 11 & r, & حدوث انتهاك للخصوصبية & 7 \\
\hline$\varepsilon$ & $\Gamma, \varepsilon 0$ & حدوث إساءة في استخدام المعلومات السرية & $\bar{V}$ \\
\hline $\mathrm{V}$ & ए,§) & حدوث خلط في الحسابات & $\Lambda$ \\
\hline 14 & $r, r q$ & أعمال غير مسموح بها قانونا (متل غسل الأموال والاحتكار) & 9 \\
\hline 0 & $\Gamma, \varepsilon r$ & أخطاء في النماذ ج الخاصة بالمنتجات المختلفة للبناك & 1 . \\
\hline 9 & $\Gamma, \Gamma \leqslant$ & عدم التواصل المستمر مع العملاء & 11 \\
\hline T & $\Gamma, \varepsilon V$ & خطاً في الاستعلام والاستقصاء عن العملاء & TY \\
\hline$r$ & $r, \leqslant 0$ & تخطي للحدود المسموح بها لعمبل الائتمان & 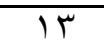 \\
\hline$\Lambda$ & $r, r q$ & حدوث نزاع أو اختلاف الرأى حول أداء الخدمات & $1 \leq$ \\
\hline
\end{tabular}

تحليل نتائج محور حوافز العاملين: نتائج الدراسة الميدانية لمحور حوافز العاملين اثتتت اتفاق عينة الدراسة على ترتيب عناصر حوافز العاملين حسب أهميتها وفقاً للمنوسط

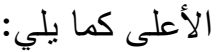

\begin{tabular}{|c|c|c|c|}
\hline الأهميبية & المتوسط & العبارات & العبارة \\
\hline$r$ & $r, \mathrm{r} \Lambda$ & التمييز بين العاملين & 1 \\
\hline$\varepsilon$ & $r, \Gamma \wedge$ & خسائر ننتجة للبيئة الغير آمنة للعمالة (عناصر الصحة والأمُان) & r \\
\hline r & $\Gamma, \varepsilon \varepsilon$ & مخالفة لقوانين العمل بالنسبة للتعويضات والمزايا وانهاء الخدمة & r \\
\hline 1 & $r, \varepsilon \vee$ & تجمعات غير رسمية (منواطئة) بين العاملين بالبنك & $\varepsilon$ \\
\hline
\end{tabular}

\section{المئوسيايت}

يوصي البحث لضمان نجاح عملية اعادة الهيكلة لتحسين الاداء المالي في البنك الزراعي المصري (بنك التتمية والائتمان الزراعي سابقا) اتباع ما يلي:

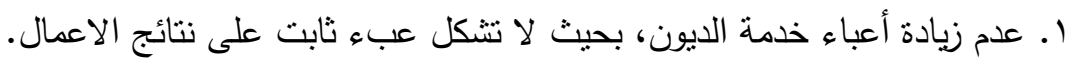


r. محاولة الالتزام بتجانس مصادر الاموال باستخداماتها من حيث المدة، والا فان عدم

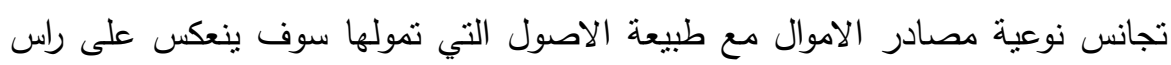
المال العامل، مما يعرض البنك لدخول مرحلة الفثل المالي.

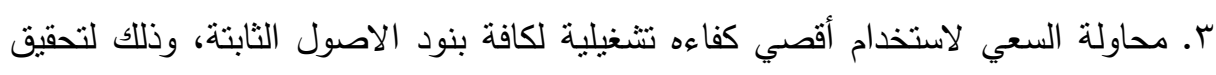

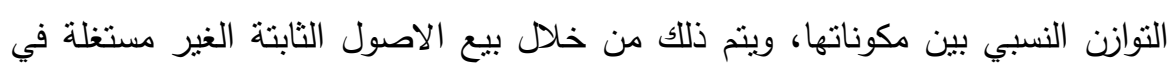

العملية الانتاجية، واعادة استثماراتها بالتوسع في بيع الاصول التئن الثابتة الانتاجية المستغلة.

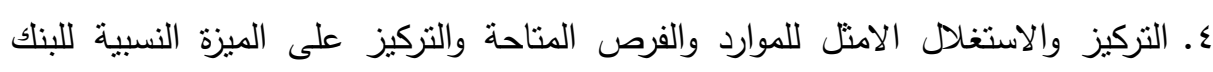

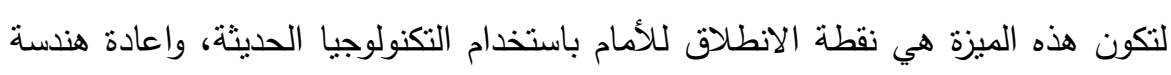

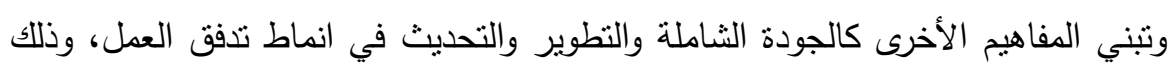
لتحقيق كفاءه الاداء المرغوب فيه عند اعادة الهيكلة سواء بالداخل تجاه الادارة او بالخارج

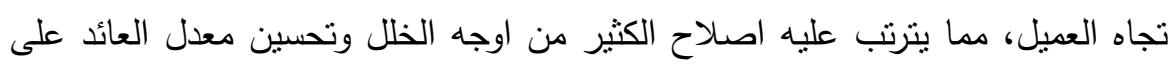

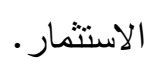

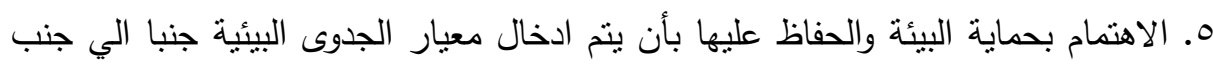

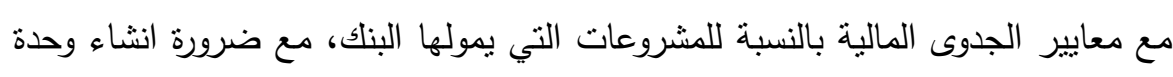
تقييم بيئي في كل بناك وتدعم بالمختصين في هذا المجال، وذلك حتي ينبني النمو الاقتصادي على صيانة واستدامة قاعدة الموارد الطبيعية من المنظور البيئي.

\section{ant}

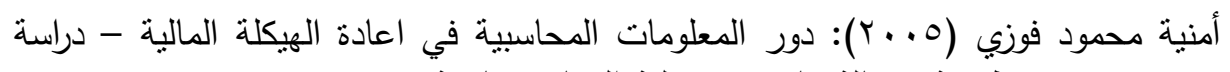
تطبيقية. رسالة ماجستير ، كلية التجارة، جامعة عين شمس.

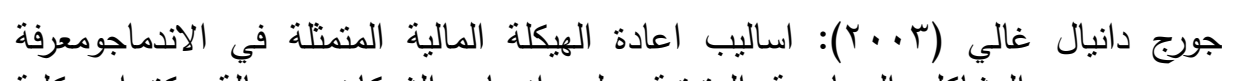

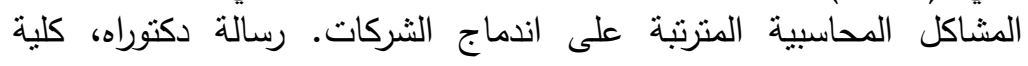
التجارة، جامعه عين شمس.

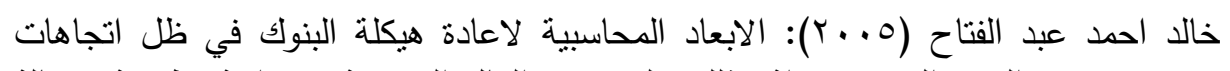

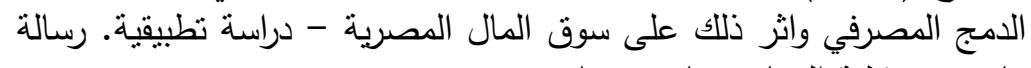
ماجسنير ، كلية التجارة، جامعه بنها. 


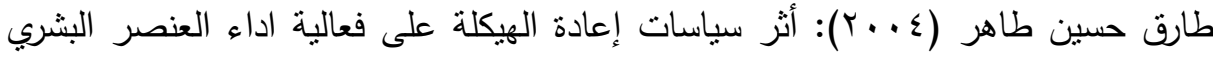

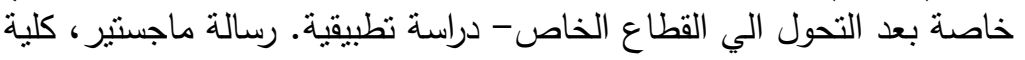
التجارة، جامعه عين شمس.

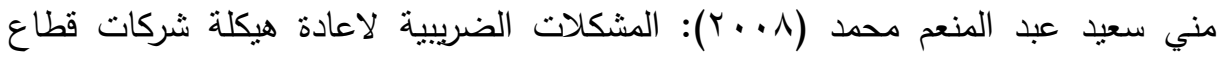

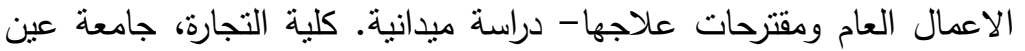

شمس.

مجلة البنك الزراعي المصري (1 ( †): مجله شهرية.

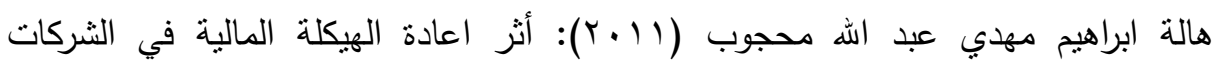

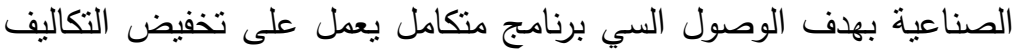

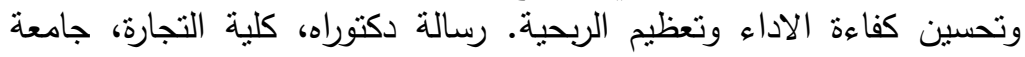

$$
\text { عين شمس. }
$$

Stook and Shear: Restructure \& Analyzing banking Risk: A Framework for Assessing Corporate Governance and Financial Risk Management. World Bank, Washington, D.C. 2006, P.4. 
أميرة محمد محمد المعناوي وآخرون

\title{
RESTRUCTURE AS A PROPOSED APPROACH FOR \\ IMPROVING FINANCIAL PERFORMANCE IN THE \\ MAIN BANK FOR DEVELOPMENT AND \\ AGRICULTURAL CREDIT FROM AN \\ ENVIRONMENTAL PERSPECTIVE
}

\section{Amira M. Elmanawi ${ }^{(1)}$; Mohamed A. Khalifa ${ }^{(2)}$ \\ Mohsen M. El-Batran ${ }^{(3)}$; Shamel El-Hamawi ${ }^{(2)}$ and Khalid H. Ahmed ${ }^{(2)}$}

1) Post graduate, Institute of Environmental Studies \& Research, Ain Shams University 2) Faculty of Commerce, Ain Shams University 3) Faculty of Agriculture, Cairo University

\begin{abstract}
The banking reformation program adopted by Egyptian banks and supported by the state's powers drives at reinforcing its validity and credibility, so, the Egyptian Agricultural Bank (Ex-Development and Agricultural Credit) in order to go through this experience, by this a good internal and external reputation under the environment Law no. (4), of 1994 and revised by Law no. (9), of 2009. The restructure processes are targeting a procedure of necessary correction of technical, economic, and financial structures of an organization from an environmental perspective in a way that enables banks to survive in business world.
\end{abstract}




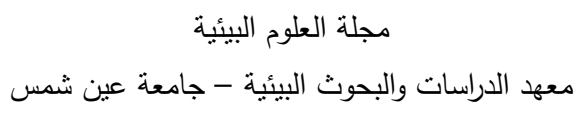

In Light of the research and expected implementation of the process of restoring the financial structure, a comparative analytical study is conducted to measure the effect of some problems affecting the banking performance as a basis for reaching a proposed accounting framework to restore the financial structure from the environmental perspective, the research is based on the use of SPSS method by determining the $\mathrm{T}$ test $\mathrm{F}$ test as well as the use of quantitative analytical descriptive method based on the design and application of simple and multi-step regression model to reach the results. The research includes two types of variables: the independent variable is the restructuring of the financial structure - the control and administrative restrictions - the sovereign declarations - the efficiency of the work - the efficiency of the productivity and the dependent variable includes the maximization of profitability and derived from it (reducing costs - improving efficiency performance - maximizing profits- incentives- System of Credit and Marketing).

This research recommends that banks in general, and the Egyptian Agricultural Bank in particular should focus and optimal utilization of resources and available opportunities; focusing as well on the relative advantage of the bank, as it becomes the launching point using modern technology. 